\title{
Development and characterization of microsatellite markers for genetic studies of a Cerrado ant, Odontomachus chelifer (Formicidae: Ponerinae)
}

\author{
Alessandra S. M. Lemos*, Marianne Azevedo-Silva, Salatiel Gonçalves-Neto, Luis F. P. Salles, Mariana Pereyra, \\ Anete P. Souza, Paulo S. Oliveira.
}

\begin{abstract}
Odontomachus chelifer are ants widely distributed in the Brazilian cerrado that belong to the group of the poneromorphs. The species is polygynous (more than one functional queen per nest) and participates in several important interactions such as seed dispersal. It is known that $O$. chelifer are susceptible to habitat fragmentation, which is capable of affecting the genetic diversity in their nests. In ants, the genetic variation of the colonies is directly influenced by polygyny, which can be mediated by environmental factors such as scarcity of resources. Thus, it is important to understand the potential effects of habitat fragmentation on polygyny and genetic structure of $O$. chelifer in order to conserve their ecological populations and roles. For this purpose, in this work we developed microsatellite markers for the species to investigate their genetic diversity and polygynous habit, as well as their possible associations with border effects in the Cerrado.
\end{abstract}

Key words:

Ants, microsatellites, edge effects.

\section{Introduction}

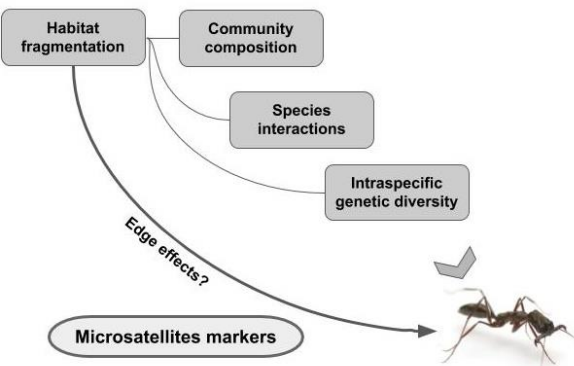

In this study, we developed microsatellite molecular markers to investigate genetic diversity and functional polygyny in Odontomachus chelifer colonies, and their possible association to edge effects in cerrado.

\section{Results and Discussion}

We developed a microsatellite-enriched library, based on hybridization capture with $(\mathrm{CT})_{8}$ and $(\mathrm{GT})_{8}$ biotin-linked probes and magnetic-coated beads. From this library, we sequenced 103 positive clones, in which 94 repeat motifs were identified, revealing a high enrichment performance. A total of 42 microsatellite loci were designed for $O$. chelifer, with most of them presenting dinucleotide motifs (Image 1). Thirty-one markers were successfully amplified by polymerase chain reaction (PCR) and 12 of them showed evidence of polymorphism. For microsatellite polymorphism characterization, 30 workers from different nests from a cerrado reserve in Mogi-Guaçu-SP were genotyped for the 24 best amplified loci.

To evaluate the impact of habitat fragmentation on genetic diversity in $O$. chelifer colonies, 15 workers from 12 nests from the same cerrado reserve (6 located at edge, and 6 in the interior of a fragment) are being genotyped for polymorphic markers.

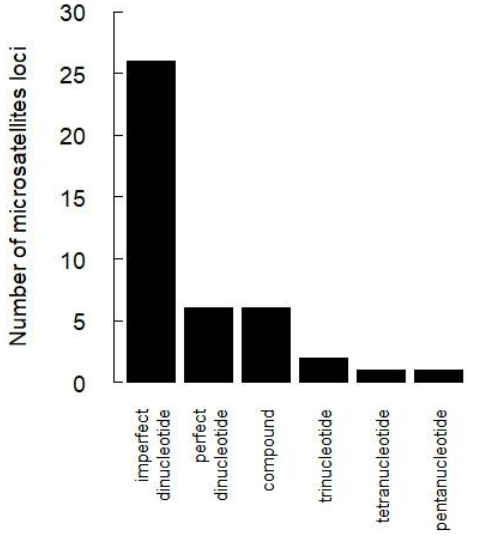

Image 1. Number of microsatellite loci per repeat motif type.

\section{Conclusions}

Microsatellite markers were developed for $O$. chelifer, which will allowed us to estimate allelic richness, expected and observed heterozygosity in colonies of this species. We will also be able to perform kinship reconstructions to infer polygyny in colonies. Furthermore, our work provides molecular tools to investigate factors that shape the genetic response of ant colonies to fragmentation, including polygyny and genetic variation within them, opening new avenues for future studies.

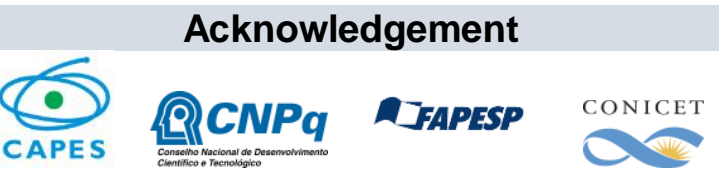

Azevedo-Silva, M.; Mori, G. M.; Souza, A. P. e Oliveira, P. S. Conserv. Genet. Resour. 2015, 7, 459.

Billotte, N.; Lagoda, P. J. L.; Risterucci, A. M. e Baurens, F. C. Fruits. 1999, $54,277$.

Salles, L. F. P.; Christianini, A.V. e Oliveira, P. S. J. Insect Conserv. 2018, 22 647. 